\title{
Eksistensi Kepentingan Global Amerika Serikat dalam Konflik Tiongkok-Taiwan
}

\author{
Syahbuddin
}

STKIP Taman Siswa Bima

oribedo70@gmail.com

\section{Artikel Info}

Tanggal Publikasi

$2019-12-30$

\section{Kata Kunci}

Eksistensi

Kepentingan Global

Konflik

\begin{abstract}
Abstrak
Penelitian ini bertujuan untuk menelaah eksistensi kepentingan global Amerika Serikat dalam konflik Tiongkok-Taiwan. Konflik Tiongkok-Taiwan sejak berakhir perang dunia kedua hingga masa kontemporer. Penelitian ini menggunakan metode penelitian sejarah yang terdiri dari empat langkah yaitu heuristik, kritik, Interprerasi dan historiografi. Peneliti menggunakan pendekatan politik dan ekonomi untuk menjelaskan kepentingan ekonomi, politik dan militer terhadap pihak-pihak yang terlibat. Hasil penelitian ini menyimpulkan bahwa konflik antara ChinaTaiwan disebabkan adanya perbedaan pandangan mendasar mengenai status Taiwan sehingga antara keduanya gagal menemukan titik temu di antara keduanya. Pemerintah Taiwan berpandangan bahwa Taiwan merupakan sebuah negara yang berdaulat dengan nama resmi Republic of China (ROC)/Taiwan. Sebaliknya, pemerintah China menegaskan bahwa eksistensi Taiwan telah berakhir sejak tahun 1949 yang selanjutnya digantikan oleh PRC. Oleh karena itu, pemerintah China menilai bahwa Taiwan tidak berhak mengklaim sebagai pemerintah yang sah di Taiwan. Sedangkan keterlibatan Amerika Serikat dalam konflik Cina-Taiwan disebabkan kebangkitan China baik dalam bidang ekonomi dan militer telah meningkatkan ketakutan dan ancaman terutama pada sekutu-sekutu Amerika Serikat terutama Taiwan sebagai sekutu lama. Pososi AS, dalam konflik ini memperlihatkan sikap yang ambigi. Disatu sisi tetap menjaga hubungan baik dengan Cina dengan menyetujui Joint Communique pada tahun 1979. Di sisi lain, Amerika Serikat membantu Taiwan karena memiliki posisi yang strategis baik di bidang ekonomi, politik maupun militer.
\end{abstract}

\section{PENDAHULUAN}

Asia Pasifik merupakan kawasan paling strategis dan dinamis baik dari aspek ekonomi, politik maupun militer. Keamanan internasional secara umum sangat ditentukan oleh bagaimana dinamika dan interaksi keamanan di kawasan ini. Posisinya yang strategis tersebut mengakibatkan konstelasi konflik serta kerja sama yang tidak hanya melibatkan negara di kawasan itu tetapi juga melibatkan negara lain. Di kawasan ini mempertemukan kekuatan besar dunia seperti Amerika Serikat, Jepang, Rusia dan bahkan new emerging superpower, China. Oleh karena itu dalam tulisan ini akan dibahas konflik Tiongkok (China)-Taiwan dimana Amerika melibatkan diri sebagai wujud interests global-nya di kawasan Asia Pasifik.

Kawasan Asia-Pasifik merujuk pada kawasan yang mencakup negara-negara Asia-Timur dan Asia Tenggara. Kawasan ini cukup luas dan mencakup banyak negara di dalamnya, seperti Jepang, Korea, China, Taiwan dan Hong Kong, serta seluruh negara anggota ASEAN dan Australia, yang pernah terlibat Perang Pasifik dalam Perang Dunia II. Tulisan ini akan membahas konflik China dan Taiwan serta intervensi Amerika Serikat.

Setelah melalui era kolonial yang dinyatakan dengan pengembalian Hongkong kepada negara Tiongkok oleh Inggris pada 1 Juli 1997, dalam sebuah upacara yang dihadiri Perdana Menteri Inggris, Tony Blair, Pangeran Charles dari Wales, Presiden Tiongkok Jiang Zemin dan Sekretaris Negara Bagian 
Madeleine Albright secara resmi Hongkong kembali ke pangkuan China. Pengembalian Hongkong ke Tiongkok tercapai setelah terjadi perundingan panjang selama dua tahun yaitu 26 September 1984 ditandatanganinya sebuah deklarasi tentang Hongkong setelah masa kontraknya habis pada 30 Juni 1997.

Berdasarkan isi deklarasi di atas Hongkong memperoleh status Special Administration Regions (SAR) adalah sebuah daerah di China yang menggunakan prinsip "Satu Negara Dua Sistem" (One Country Two System).Di bawah kebijakan "Satu Negara Dua Sistem” Hongkong berhak menikmati otonomi dari pemerintah RRC seperti pada sistem hukum, mata uang, bea cukai dan imigrasi. Namun pada prakteknya, masih banyak kebebasan dan aspirasi masyarakat Hongkong yang dicampuri dan dikekang oleh pemerintah pusat di China. Seharusnya urusan yang ditangani oleh pemerintah China hanyalah masalah pertahanan nasional dan hubungan diplomatik (https://zakariaselbilad. wordpress.com/ 2008/11/19/sejarah-dan-perkembangan-hongkong, diakses 2 Januari 2018).

Sedangkan masalah Macau, sejak Juni 1986, Tiongkok dan Portugal mulai berunding tentang nasib Macau sehingga pada 13 April 1987 Portugal mengembalikan Macau kepada Tiongkok. Pemerintah Republik Rakyat China dengan Portugis menandatangani Joint Declaration yang berisi keinginan China untuk memberikan otonomi khusus kepada Macau yaitu Special Administrative Regions (SAR). China juga menekankan bahwa esensi dari SAR ini adalah Macau akan memiliki otoritas yang lebih tinggi dibandingkan daerah-daerah lainnya yang tidak memiliki SAR dalam mengatur daerahnya kecuali masalah politik luar negeri dan pertahanan keamanan yang tetap menjadi wewenang China. Macau menjadi daerah administrasi khusus Tiongkok dan berhak mengatur urusannya sendiri hingga tahun 2049. Dengan demikian Hongkong dan Macau berkedudukan sebagai daerah istimewa dalam wadah Special Administrative Regions (SAR).

Bergabungnya dua daerah di atas menyebabkan Tiongkok (China) berambisi untuk menyatukan Taiwan dalam satu China. Upaya mencegah Taiwan merdeka adalah masalah penting bagi RRC karena menyangkut kredibilitas di mata rakyatnya. Untuk tetap menjaga kredibilitas tersebut, Beijing bertekat menempuh segala cara, termasuk invasi ke Taiwan meskipun nantinya RRC akan berhadapan juga dengan AS. Kesungguhan China itu dapat dilihat dengan terajdinya krisis Selat Taiwan yang telah berlangsung selama dua kali. RRC mengklaim bahwa Pulau Formosa yang berganti nama menjadi Taiwan adalah bagian dari RRC berdasarkan sejarah yang tercatat tahun $304 \mathrm{M}$ dengan nama Pulau Yizh Liuqiu. Di masa Dinasti Sui, penduduk China daratan mulai memasuki pulau ini. Berbagai dinasti China selanjutnya juga tercatat menguasai pulau ini hingga akhirnya terjajah oleh Jepang.

Bagi China, Taiwan adalah pulaunya yang hilang. Taiwan memiliki arti yang sangat penting dan strategis, sehingga kepentingan untuk reunifikasi tidak dapat ditawar lagi. Kehilangan Taiwan akan memberikan Implikasi yang mendalam dan cukup kompleks bagi China. Deklarasi kemerdekaan oleh Taiwan dianggap setara dengan deklarasi perang. Jika pemerintah China gagal mempertahankan Taiwan, maka hal itu akan memicu pemberontakan serupa di Tibet, Xinjiang dan beberapa tempat lainnya. Sedangkan bagi para elit China, lepasnya Taiwan berarti kelemahan China, sedangkan bersatunya Taiwan berarti kekuatan China. Hal senada juga diungkapkan oleh Yan Xuetong, direktur Institute of International Studies Universitas Tsinghua, "If China lacks th ability to preserve national unity, it cannot rise to be a world power, nor can it achieve national rejuvenation" (Deng, 2008: 256 257).

Menanggapi masalah di atas, Kementerian Luar Negeri China mengatakan Taiwan adalah masalah internal Tiongkok (China). Hanya ada satu China di dunia dan pemilu yang digelar negara kepulauan itu tidak merubah kenyataan atau penerimaan internasional. "Hanya ada satu China di dunia, daratan dan Taiwan keduanya milik satu China. China tak akan tidak akan membiarkan kedaulatan serta integritas teritorialnya rusak. 
Ambisi Tiongkok terhambat kepentingan Amerika Serikat dikawasan Asia Pasifik khususnya Taiwan. Kepentingan Amerika Serikat di Asia Pasifik antara lain perdagangan bebas, kebebasan navigasi maritim dan pemerintahan yang demokratis di beberapa negara mencirikan nilai-nilai yang sama dengan kepentingan AS. Hal inilah yang mendorong Amerika Serikat melakukan intervensi di Asia Pasifik umumnya dan hubungan Tiongkok dengan Taiwan. Amerika Serikat dalam kaitannya dengan hal ini berdiri di belakang Taiwan untuk berusaha menahan laju China.

\section{METODE PENELITIAN}

Metode adalah cara atau prosedur untuk mendapatkan objek (Pranoto, 2010:11). Seangkan Helius Sjamsuddin menjelaskan bahwa metode berarti cara, jalan, petunjuk pelaksana atau petunjuk teknis yang sistematis dalam suatu pendidikan ilmu tertentu untuk mendapatkan obyek (Sjamsuddin, 2007:24). Sedangkan J. Garragham menjelaskan metode penelitian sejarah adalah seperangkat aturan atau prisip sistematis untuk mengumpulkan sumber-sumber sejarah secara efektif, menilainya secara kristis, dan mengajukan sintesis dari hasil-hasil yang dicapai dalam bentuk tertulis (Abdurrahman, 2007:53).

Berdasarkan pengertian di atas para ahli ilmu sejarah sepakat untuk menetapkan empat kegiatan pokok di dalam cara meneliti sejarah. Gottschalk (1983) mensistematisasikan langkah-langkah dalam metodologi sejarah itu sebagai berikut; (a) mengumpulkan obyek yan berasaldari suatu zaman dan mengumpulkan bahanbahan tertulis dan lisan yang relevan; (b) menyingkirkan bahan-bahan yang tidak autentik; (c). menyimpulkan kesaksian yang dapat dipercaya berdasarkan bahan-bahan yang autentik; (4) menyusun kesaksian yang dapat dipercaya itu menjadi kisah atau penyajian yang berarti (Abdurrahman (2007:54).

Langkah pertama adalah Heuristik, GJ. Renier menjalaskan teknik mengumpulkan sumber disebut heuristik yang berarti memperoleh (Abdurrahman, 2008:64). Selanjutnya dijelaskan bahwa heuristik adalah suatu teknik, suatu seni bukan suatu ilmu oleh karena itu heuristik tidak mempunyai peraturan-peraturan umum. Dalam mengumpulkan sumber peneliti melakukan studi pustaka. Menurut Koentjaraningrat teknik kepustakaan merupakan cara pengumpulan data bermacam-macam material yang terdapat di ruang kepustakaan, seperti koran, buku-buku, majalah, naskah, dokumen dan sebagainya yang relevan dengan penelitian (Koentjaraningrat, 1983:420). Dengan demikian data yang dikumpulkan berupa data-data sekunder. Setelah peneliti mengumpulkan sumber-sumber sejarah tahap berikutnya adalah kritik sumber (verifikasi) untuk memperoleh keabsahan (Abdurahman, 2008:68). Tahap ini dapat dilakukan baik kritik eksternal maupun kritik internal.

Setelah sumber tersebut terkumpul maka langkah selanjutnya adalah melakukan kritik terhadap sumber, baik itu kritik intern maupun ekstern. Kritik ekstern berupa menguji keaslian dari sumber berupa segi-segi luarnya misalnya mengujian dengan pertanyaan berupa kapan sumber itu dibuat, siapa pembuat sumber sejarah tersebut, dari bahan apa sumber itu dibuat, apakah sumber itu masih dalam bentuk asli? Setelah itu kita melakukan kritik intern yang menguji isi kandungan sumber tersebut dengan pertanyaan apa dan bagaimana isi kandungan sumber tersebut. Hal ini dapat dilakukan dengan kritik internal negatif dan kritik internl positif.

Tahap selanjutnya adalah interpretasi atau analisis. Interpretasi berarti menafsirkan atau memberi makna kepada fakta-fakta adau bukti-bukti sejarah (Daliman, 2012:81). Tugas peneliti memberikan penafsiran dalam kerangka memugar suatu rekonstruksi masa lampau. Analisis sendiri bertujuan melakukan sintesis (menggabungkan) atas sejumlah fakta yang diperoleh dari sumbersumber sejarah dan bersama teori disusunlah fakta itu dalam suatu interprestasi yang menyeluruh (Abdurrahman, 2007:73). Tahap terakhir adalah histiriografi yaitu proses penyusunan fakta sejarah dan berbagai sumber yang telah diseleksi dalam bentuk tulisan sejarah (Sulasman, 2014:147). Model penjelasan yang digunakan adalah kausalitas untuk meneropong faktor-faktor penyebab sebuah 
peristiwa terjadi. Menurut Carr (1971), dalam sejarah dapat dibedakan sebab umum (general cause, findamental sause), dan sebab khusus (direct cause, immadiate cause) atau yang menjadi pemicu (trigger). Kausalitas merupakan model penjelasan sejarah dengan merangkai fakta dalam hubungan sebab akibat (cause and effect). Hukum sebab akibat mengingatkan bahwa setiap fenomena merupakan akibat dari sebab sebelumnya (Pranoto, 2010:45).

\section{HASIL DAN PEMBAHASAN}

\section{Konflik China-Taiwan}

Konstelasi politik intemasional di kawasan Asia Pasifik diwarnai oleh beberapa dinamika salah satunya adalah dinamika hubungan antara China dan Taiwan. Hubungan kedua negajra dapat dikatakan sebagai hubungan "subordinasi". Konflik China-Taiwan berawal sejak April 1927, dimana kaum Nasionalis pimpinan Ciang Kai Shek dengan kaum komunis pimpinan Mao Zedong. Dalam perkembangan selanjutnya kedua kubu kaum nasionalis mendirikan pemerintahan China nasionalis di Nangking sedangkan sedangkan kaum komunis mendirikan pemerintahan komunis yang berpusat di Kiangshi (Agung, 2012: 180). Pertentangan dua kubu ini membawa mereka dalam Perang Saudara memperebukan kekuasaan. Kaum komunis di bawah Mao Zedong mulai membangun kantung kantung komunis bergaya Soviet di pedesaan. Mao Zedong mengumpulkan tentara gerilya kecil yang menyerang kereta api pasokan Kuomintang, pasukan pemandu, dan target sekunder lainnya. Lebih penting lagi, komunis Mao Zedong memperoleh pengikut di seluruh pedesaan China (Ye dan Tianyou, 2007: 89).

Pada tahun 1931, Jepang menyerang Manchuria, hal ini berarti ancaman buat China. Pasukan Jepang kembali berusaha menduduki Tiongkok dan berhasil merebut Nanking, ibu kota Tiongkok pada 13 Desember 1937. KMT tidak mampu menghadapi serangan Jepang. Kemudian, pihak KMT dan PKC kembali membentuk persatuan. Walaupun kaum komunis dan nasionalis bersatu menghadapi Jepang namun perbedaan idologi membuat koalisi tersebut tidak bertahan lama. Perang saudara pecah, hal ini dipicu oleh perintah Chiang kai Shek bahwa tentara Jepang tidak boleh tunduk kepada siapapun kecuali kepada pemerintah Chungking dan tentara Jepang sebelum itu harus tetap pada tempatnya masing-masing untuk menjaga keamanan dan ketertiban (Soebantardjo, 1960: 54).

Jepang menyerah kepada pihak sekutu pada 14 Agustus 1945, Jepang menyerahkan Taiwan kepada Tingkok. Penyerahaan kekuasaan dilakukan oleh Jepang dengan penandatanganan Instrumen Penyerahan pada tanggal 15 Agustus 1945, dan penyerahan secara formal pada tanggal 25 Oktober 1945 (Islami, 2013: 71). Pasca menyerahnya Jepang keadaan Tiongkok semakin memburuk karena Nasionalis dan Komunis saling berebut posisi di Tiongkok. Pada mulanya pasukan Nasionalis yang lebih dulu menaklukan kota-kota besar, mulai khawatir dengan Tentara Merah yang lebih dulu menguasai daerah pedesaan dan pegunungan yang sangat luas dan dengan cepat dapat menguasai daerah-daerah bekas kependudukan Jepang. Oleh karenanya, Chiang Kai Shek meminta bantuan Amerika Serikar untuk menyelesaikan permasalahan di Tingkok. Presiden Harry S. Truman mengutus Jendral George C. Marshall pada 15 Desember 1945 yang bertindak sebagai mediator persengketaan antara Nasionalis-Komunis. Namun, sepeninggal Marshall pertempuran antara Nasionalis dan Komunis semakin meluas (Darini, 2008, 20-21).

Kaum komunis yang sudah menguasai Tiongkok bagian utara mulai merambah ke bagian selatan sungai Yang Tze, dan berhasil merebut markas KMT di Nanking. Akibatnya KMT kemudian memindahkan markasnya ke Kanton. Kondisi ini membuat Chiang Kai Shek bertindak lebih kejam dan diktator, bahkan ia membunuh siapapun yang tidak bersedia memberikan dukungan. Di lain pihak, komunis memanfaatkan hal tersebut untuk menarik simpati rakyat Tiongkok melalui propaganda Landreform. Jumlah pendukung yang semakin besar membawa kemenangan pihak Komunis. Tentara di bawah kontrol Mao di Shaanxi berkembang di akhir tahun 1935 dengan beberapa ribu pendukung komunis yang telah bersatu dalam perang gerilya dengan pasukan Kuomintang. 
Penduduk yang di bawah komando Tentara Merah meningkat dari 2 juta menjadi 95 juta, begitu juga dengan pasukan merah jumlahnya meningkat dari 30.000 menjadi hampir satu juta jiwa.

Perang saudara yang berlangsung sejak tahun 1927-1949 dimenangkan oleh kaum komunis. Mao Zedong mendeklarasikan berdirinya RRC pada tanggal 1 Oktober 1949. RRC mendapatkan pengakuan kedaulatan dari Uni Soviet pada tanggal 2 Oktober 1949, India pada tanggal 30 Desember 1949, Inggris pada tanggal 1 Januari 1950. Kemenangan kaum komunis ini tidak lepas bantuan dari Uni Soviet dan semangat juang para petani. Pada perang sipil tersebut, pasukan PNC di bawah komando Chiang Kai Shek menderita kekalahan dan mundur kepulau Formosa atau yang kita kenal sekarang dengan Taiwan. Sejak saat tersebut Republic of China (ROC) melanjutkan pemerintahannya ke pulau utama Taiwan dan sejumlah pulau kecil lainnya Jinmen, Mazu, dan Dazhen. Pihak berwenang di Beijing tidak pernah menjalankan kedaulatannya atas Taiwan atau pulau-pulau lainnya yang dikuasai pemerintah the ROC di Taipei.

Taiwan dibangun di atas sendi-sendi demokrasi sehingga banyak imigran masuk ke Taiwan. Menurut Shepherd (1993), pada waktu itu, populasi Taiwan meningkat drastis seiring kian gencarnya program imigrasi yang dilakukan. Jumlah penduduk Taiwan yang pada 1650-an hanya sekitar 100 ribu jiwa, melonjak tajam hingga 1,78 juta orang pada 1824 (Mubah, 2014:324). Namun, sampai saat ini hanya beberapa negara saja yang mengakui keberadaannya sebagai sebuah negara bahkan PBB hanya mengakuinya sebagai provinsi dari negara China dengan dikeluarkan dari representasi Tiongkok di PBB tahun 1971. Hal ini tentu saja menyulistan Taiwan dalam kancah kerjasama internasional.

Pada masa pemerintahan Chiang Ching-kuo, ruang gerak Taiwan semakin sempit. Upaya Tiongkok melakukan normalisasi hubungan dengan Amerika Serikat menghasilkan U.S-China Joint Communique pada 17 Agustus 1979. Berdasarkan kesepakatan tersebut Amerika Serikat mengakui hanya ada satu China yang sah yaitu Tiongkok, dan Taiwan adalah bagian dari Tiongkok.

Kondisi tersebut mendorong Ching Cheng Kuo untuk membuat kebijakan terhadap Tiongkok 'Three no Policy' artinya tidak ada kontak, negosiasi, dan kompromiantara Taiwan-Tiongkok. Sikap Taiwan terhadap konsep one country two systems dari Tiongkok dengan jelas dinyatakan oleh Lee Teng-hui dalam wawancara dengan The Washington Post pada November 1997. Tucker (2009), Lee menyatakan bahwa "Taiwan is already independent ... Taiwan is an independent, sovereign country." Karena itu, sejak awal 1998, Lee mulai berbicara atas nama Taiwan sebagai negara merdeka yang berdaulat. Dia mendesak Beijing menempatkan Taiwan dan China sebagai dua entitas politik yang setara dan bukannya memposisikan Taiwan sebagai subordinat China. Bagi Lee, konsep one country two systems hanya sesuai diterapkan pada bekas koloni Inggris seperti Hongkong, tidak tepat diberlakukan di Taiwan (Mubah, 2014, 326).

Kunjungan Lee Teng Hui ke berbagai negara dalam usaha mencari dukungan ini memicu kemarahan pemerintahan RRC, karena dalam hal ini Taiwan berusaha mengambil sikap yang jelas bertentangan dengan cita-cita RRC dalam menyatukan wilayah China kembali. Dari beberapa kali perjalanan ke luar negeri, kunjungan yang paling menyita perhatian banyak pihak adalah kunjungan Lee ke almamaternya, Universitas Cornel AS, yang berlangsung tanggal 9-10 juni1995. Kunjungan ini tidak hanya memicu serangkaian serangan verbal dan ancaman militer dari Beijing, namun juga menyebabkan hubungan lintas selat yang baru dibangun menjadi renggang kembali selain itu juga menyebabkan peningkatan keamanan militer. China membalas serangkaian kunjungan dengan mengeluarkan pengumuman percobaan misil pada 7 Juli 1995 oleh People's Liberation Army (PLA) yang diarahkan ke Taiwan. Hal ini dilakukan RRC sebagai bentuk ketidaksetujuan terhadap sikap presiden Lee. Peristiwa tersebut memicu ketegangan antar-selat hingga ketiga kalinya di Selat Taiwan. Serangan misil ini dilakukan dalam dua tahap: pertama pada pertengahan 1995, dimana RRC mengirim sinyal ancaman kepada pemerintahan Taiwan di bawah pemerintahan Lee Teng Hui, terhadap kebijakan luar negeri Taiwan yang semakin menjauh dari Kebijakan Satu China. Misil kedua 
yang dilancarkan pada awal tahun 1996, mereka berniat untuk mengintimidasi pemilihan presiden yang dilaksanakan secara langsung untuk pertama kalinya di Taiwan pada tanggal 23 Maret 1996. Sikap lanjut dari China dimana Presiden RRC pun merespon Taiwan tersebut dengan mengeluarkan "White Paper" kedua pada pidato kepresidenannya tanggal 21 Februari 2000 yang dikenal dengan "Three Ifs" sebagai bentuk peringatan keras dalam menjaga keutuhan seluruh wilayah China (Kan, 2014:68).

Pengganti Lee sebagai presiden Taiwan adalah Chen Shui-Bian dari Democratic Progressif Party (DPP) yang menggantikan Lee setelah memenangkan pemilu 20 Maret 2000. DPP merupakan partai yang konsisten memperjuangkan kemerdekaan Taiwan. Pada saat pelantikannya, Chen menyampaikan respon terhadap ancaman China dengan tetap mempertahankan kekuatan oposisi di pulau dengan mengajukan "Five Noes" (Lima Pernyataan Tidak), kebijakan yang menyertakan sumpah untuk tidak meminta kemerdekaan Taiwan terhadap RRC sebagai upaya dalam menjaga perdamaian di kawasan selat Taiwan. Pernyataan Chen Shui-Bian ini menyebabkan China makin geram. Chen juga berupaya mengembalikan posisi Taiwan sebagai anggota Perserikatan Bangsa-Bangsa (PBB), namun besarnya pengaruh China di kancah politik internasional menyebabkan semua usaha Taiwan ke arah itu gagal.

Reaksi China atas sikap Taiwan dengan menerbitkan undang-undang Anti Pemisahan (AntiSecession Law) pada tahun 2005. Undang-undang yang disahkan oleh konferensi ke-3 Kongres Rakyat Nasional dari pemerintah RRC. Terdapat tiga skenario dalam UU yang memprekondisikan penggunaan "tindakan non damai" dalam menghadapi Taiwan: jika separatis Taiwan mengambil tindakan untuk memisahkan Taiwan dari RRC dengan segala tujuan atau segala bentuk; terdapat insiden besar yang menjadi sebuah petunjuk Taiwan terhadap usaha memisahkan diri dari RRC; dan kemungkinan untuk unifikasi secara damai sudah dalam tahap melelahkan.

Seiring dengan pergantian pemerintahan, Presiden Ma Ying-Jeou dan Wakilnya Vincent Siew terpilih menjadi Presiden Taiwan pada 20 Mei 2008 dengan dukungan 58,45 persen suara. Presiden Ma Ying-Jeou menginginkan kerjasama yang lebih baik dengan China, mengingat keduanya mewarisi filosofi, tradisi, dan nilai kebudayaan yang sama. Sinyal awal membaiknya hubungan politik RRC dan

Taiwan ditunjukkan saat Presiden China Hu Jintao mengirimkan telegram atas terpilihnya Ma Ying-jeou sebagai pada tahun 2014 silam, China dan Taiwan mengadakan pembicaraan pertama di level pemerintahan pasca perpisahan mereka di tahun 1949 (https://www.bbc.co.uk/news/world-asiachina-26129171 diakses pada 11 Maret 2019 pukul 17.25). Satu hal yang menarik dimana pada 7 November 2015, Presiden China Xi Jinping dan Presiden Taiwan Ma Ying-jeou bertemu di Singapura untuk pertama kalinya sejak kedua negara berpisah lebih dari 60 tahun lalu. Pertemuan tersebut menunjukan bahwa adanya inisiatif untuk mempererat hubungan bilateral dan memperbaiki hubungan yang kelam di masa lalu. Dalam pertemuan itu kedua pemimpin berbicara tentang mengembangkan hubungan kerjasama antar keduanya dan membuka lebih banyak pintu-pintu baru untuk hubungan kerja sama antar keduanya. Upaya perbaikan hubungan bilateral juga dilanjutkan oleh Tsai Ing-Wen dari Partai Demokrat Progresif (DPP) yang memenangkan pemilu tahun 2016. Walaupun kedua presiden terakhir memilih membuka buhungan bilateral dengan China namun kedua negara tetap pada pendiriannya masing-masing.

\section{Intervensi Amerika Serikat di Asia Pasifik}

Salah satu perkembangan setelah berakhirnya Perang Dunia II yaitu adanya pertentangan antara ideologi komunis dan demokrasi liberal. Berdirinya negara komunis di China ternyata akan mempengaruhi perkembangan dunia, khususnya Asia Timur. Uni Soviet sebagai salah satu negara pemenang dalam Perang Dunia II dengan cepat menggunakan dan menciptakan peluang untuk memperbesar pengaruhnya baik di barat, timur maupun ke selatan. Mode perkembangan ini jelas mengelisahkan Barat pimpinan Amerika Serikat, sehingga Amerika Serikat merasa berkewajiban untuk mencegah berkembangnya gerakan komunis. Maka disusunlah kemudian strategi politik globalnya yang dikenal dengan istilah Containment Policy, yang berarti suatu politik bertujuan mencegah 
berkembangnya pengaruh suatu negara atau suatu sisitem politik dari pihak lawan agar pengaruh komunisme tidak meluas. Dalam konteks hubungan Tiongkok-Taiwan, AS disini melihat Tiongkok sebagai Major Threat bagi keamanan di Asia Pasifik.

Pasca Perang Dingin yang ditandai dengan runtuhnya Uni Soviet, AS mengurangi kehadirannya di Asia Pasifik dengan cara mengedepankan peranan sekutu-sekutunya dan membangun konstruksi keseimbangan strategis yang dilandaskan pada keberadaan sekutu-sekutunya di kawasan. AS menilai bahwa situasi keamanan di kawasan Asia Pasifik relatif tidak mengancam kepentingan-kepentingan AS.

Namun perkembangan kawasan Asia Pasifik yang sangat dinamis menyebabkan AS kembali memperhatikan kawasan itu dengan serius. Perkembangan signifikan terjadi di negara-negara kawasan Asia Pasifik. Bidang ekonomi dan militer, telah memunculkan kawasan Asia Pasifik sebagai pusat aktivitas dunia internasional. Munculnya China sebagai new emerging power dan great economic power, membawa Amerika Serikat kembali mengalihkan fokus perhatiannya pada kawasan Asia Pasifik dengan membangun kembali dan mengembangkan hubungan dan kerjasama dengan negara-negara sekutunya (Sari, Suwarti \& Yanyan Mochamad Yani, 2017: 6).

Kebangkitan China ini telah menghasilkan ikatan yang unik dengan AS. Keseimbangan yang kompleks antara kedua negara menghasilkan pola interaksi ketergantungan dan kepentingan yang berbeda. Pertama, kebangkitan China telah menyebabkan pembaruan dan peningkatan kolaborasi kestabilan tatanan dunia antara AS dan China yang telah membuahkan hasil pada sejumlah isu global khususnya dalam aspek ekonomi dan perdagangan. Kedua, kebangkitan China telah meningkatkan ketakutan dan ancaman. Perbedaan kepentingan dan orientasi politik antara AS dan China memungkinkan terjadinya konflik antarkedua negara (Bendini 2016, 4-5).

Berdasarkan pertimbangan di atas, Amerika Serikat merasa perlu untuk menjaga stabilitas wilayah Asia Pasifik umumnya dan Taiwan khususnya. Konflik penyeberangan di selat Taiwan antara Tiongkok-Taiwan terjadi pertama kali pada tahun 1954-1955, krisis penyebrangan Selat Taiwan kedua terjadi pada tahun 1958 (Bullard, 2004: 155). Krisis selat Taiwan juga terjadi pada tahun tahun 1962. Pada krisis pertama RRC menyerang Republik China yang pada saat itu berada di KepulauanYijiangshan, dan memaksa Republik China untuk meninggalkan Kepulauan Tachen, yang pada akhirnya RRC berhasil menguasai wilayah tersebut. Amerika Serikat, yang memang tak menyukai rezim komunis China bersekutu dengan Uni Soviet (Rusia) yang menjadi musuh AS saat perang dingin, melihat begitu besarnya pengaruh China akhirnya memutuskan untuk bersekutu dengan Republik China dan membantu mengevakuasi personel militer Republik China dari Tachen keFormosa (Taiwan). Meski berakhir dengan gencatan senjata, krisis ini akhirnya berlanjut ke krisis selanjutnya di selat yang sama. Pasca terjadinya krisis ini AS membuat suatu perjanjian dengan pihak Chiang KaiShek (Taiwan) yaitu Mutual Defence Treaty (MDT). Berdasarkan perjanjian di atas, Amerika Serikat bertanggung jawab atas keamanan maupun pertahanan Taiwan.

Di mata AS, Taiwan memiliki kedudukan yang strategis baik di bidang politik, ekonomi dan militer sebagai berikut: (a) Taiwan dapat dikatakan pro-Barat, hal ini jelas sangat menguntungkan bagi AS; (b) Posisi Taiwan di Laut China sangat menguntung bagi AS. Dengan adanya pangkalan pasukan AS di Taiwan akan terjaga jalur sumber daya, jalur perdagangan antarsekutu-sekutunya seperti Jepang; (c) Sistem sosial ekonomi di Taiwan yang bebas sesuai dengan keinginan AS; (d) Keberadaan pangkalan militer AS di Taiwan bisa menjadi semacam "peringatan” bagi Uni Soviet (Rusia sekarang) yang sedang terlibat pergumulan kekuatan di kawasan ini dengan menempatkan armadanya di Cham Renh Bey, Vietnam; (e) AS sangat berkepentingan agar sekutu-sekutunya tidak jatuh ke tangan komunis; (f) AS berkepentingan menjaga kawasan ini (Agung, 2012:185).

Krisis Selat Taiwan kedua 1958 merupakan serangan RRC terhadap Republik China (Taiwan). Selang beberapa tahun, intimidasi di kepulauan kecil di tengah selat tersebut kembali berlanjut. Kala itu, Kai-Shek dan pengikutnya masih mendiami kepulauan Matsu dan Quemoy. China akhirnya 
menggempur kedua kepulauan tersebut dan memukul pasukan Chiang Kai-Shek sehingga mundur dan menetap di Formosa (Taiwan sekarang) sampai sekarang.

Untuk meningkatkan kemandirian militer Taiwan, AS juga giat melakukan penjualan alutsista ke pihak Taiwan hingga sekarang. Tindakan yang pada gilirannya mengudang protes dari pihak RRC. Pada tahun 1954 di saat perang dingin berlangsung tepatnya setelah perang Korea usai, AS dan Taiwan membuat suatu perjanjian yang sebelumnya pada saat itu AS membantu Kuomintang beserta pengikutnya dalam pelarian dari RRC dan membantu melawan serangan dari RRC.

Di lain pihak AS juga menjaga hubungan dengan China karena kepentingan ekonomi dan politik. China melalui Shanghai Communiqué pada tanggal 28 Pebruari 1972 yang berisi Amerika Serikat mengakui bahwa baik Taipei dan Beijing sepakat bahwa hanya ada satu China. Dengan adanya perjanjian ini menggerogoti hubungan diplomatik antara AS dan Taiwan. Walaupun hubungan diplomatik resmi AS-Taiwan telah dihentikan akan tetapi hubungan tidak resmi antara AS-Taiwan tetap berjalan dalam bidang Ekonomi dan Militer. AS tetap membangun hubungan dengan Tiongkok sehingga pada 1 Januari 1979 membuka hubungan diplomatik penuh dengan AS.

Dalam hal ini, AS membangun hubungan diplomatik dengan China, tetapi juga berkomitmen untuk membantu pertahanan Taiwan. AS mendukung kebijakan "satu China”, dengan Beijing sebagai pemerintah yang sah, di lain pihak menjalin hubungan perdagangan dan militer dengan Taipei. Tiga bulan setelah normalisasi hubungan AS-China, pada 10 April 1979 AS-Taiwan menandatangani Perjanjian Taiwan Relations Act (TRA). Melalui TRA, AS tetap menjalin hubungan perdagangan, kebudayaan dan berbagai hubungan yang tidak resmi lainnya. Menurut Chang (2001:66) dalam tulisannya U.S. Policy Toward Taiwan, di bawah TRA, AS menjalankan kebijakan: (1) Memelihara dan mengembangkan hubungan kultural, perdagangan dan lainnya secara ektensif dan bersahabat di antara AS dan rakyat Taiwan, (2) Mendeklarasikan perdamaian dan stabilitas di area kepentingan politik, keamanan dan ekonomi AS dan di area yang menjadi perhatian internasional, (3) Memperjelas masa depan Taiwan akan ditentukan oleh cara-cara damai; mengangap bahwa usaha-usaha yang menentukan masa depan Taiwan, selain cara-cara damai, termasuk boikot atau embargo, merupakan ancaman keamanan dan perdamaian bagi negara-negara Pasifik Barat dan menjadi perhatian penting bagi AS, (4) Menyediakan persenjataan defensive untuk Taiwan, (5) Meyakinkan hak untuk melawan segala macam bentuk serangan atau koersi yang akan mengancam keamanan atau sistem ekonomi dan sosial rakyat Taiwan (Chang, 2001: 4).

Bersandar pada Taiwan Relations Act (TRA) yang telah berlaku sejak 1979, AS merasa berkewajiban untuk membantu dan melindungi Taiwan. Karena itu, AS tidak pernah berhenti menyalurkan bantuan ekonomi dan militer ke Taiwan. Tercatat selama 3 dekade setelah TRA diimplementasikan (1980-2010), AS telah menjual senjata ke Taiwan sebesar 25,39 miliar USD (Arms Control Association 2012). Ketika memperingati 35 tahun TRA pada 9 April 2014, 52 senator AS mengirimkan surat desakan kepada Presiden Barack Obama untuk terus meningkatkan bantuan kepada Taiwan karena "helping Taiwan make further meaningful contributions in the region is in the interest of the United States and in line with the spirit of the TRA" (Mubah, 2014:322-323). Kerjasama militer Amerika Serikat-Taiwan telah dibangun atas konvergensi kepentingan strategis, yaitu dalam membendung ekspansi komunis di Asia Pasifik selama masa perang dingin. Penandatanganan USROC Mutual perjanjian pertahanan tahun 1954 akhir, dan pendirian sebelumnya bahwa bantuan militer Amerika Serikat ke Taiwan, Amerika Serikat tidak hanya menjamin keamanan dan kelangsungan pemerintah Taiwan, tapi juga memungkinkan sesuatu yang lebih lengkap terhadap jaringan aliansi militer antara Amerika Serikat dan demokrasi di Asia Pasifik (Darmawan, 2015:2-3).

Di mata AS, Taiwan memiliki kedudukan yang strategis baik di bidang politik, ekonomi dan militer sebagai berikut: (a) Taiwan dapat dikatakan pro-Barat, hal ini jelas sangat menguntungkan bagi AS; (b) Posisi Taiwan di Laut China sangat menguntung bagi AS. Dengan adanya pangkalan pasukan 
AS di Taiwan akan terjaga jalur sumber daya, jalur perdagangan antarsekutu-sekutunya seperti Jepang; (c) Sistem sosial ekonomi di Taiwan yang bebas sesuai dengan keinginan AS; (d) Keberadaan pangkalan militer AS di Taiwan bisa menjadi semacam "peringatan” bagi Uni Soviet (Rusia sekarang) yang sedang terlibat pergumulan kekuatan di kawasan ini dengan menempatkan armadanya di Cham Renh Bey, Vietnam; (e) AS sangat berkepentingan agar sekutu-sekutunya tidak jatuh ke tangan komunis; (f) AS berkepentingan menjaga kawasan ini (Agung, 2012:185).

Masalah Taiwan makin sulit dan rumit dimana AS memainkan dua sisi yang berbeda di satu sisi AS mengakui one-China policy sesuai Shanghai Communique, tetapi di sisi lain AS berkewajiban melindungi Taiwan berdasarkan amanat TRA (Yang 2004: 10). Melalui TRA, AS tetap menjalin hubungan perdagangan, kebudayaan dan berbagai hubungan yang tidak resmi lainnya. Di bawah TRA, AS menjalankan kebijakan: (1) Memelihara dan mengembangkan hubungan kultural, perdagangan dan lainnya secara ektensif dan bersahabat di antara AS dan rakyat Taiwan, (2) Mendeklarasikan perdamaian dan stabilitas di area kepentingan politik, keamanan dan ekonomi AS dan di area yang menjadi perhatian internasional, (3) Memperjelas masa depan Taiwan akan ditentukan oleh cara-cara damai; mengangap bahwa usaha-usaha yang menentukan masa depan Taiwan, selain cara-cara damai, termasuk boikot atau embargo, merupakan ancaman keamanan dan perdamaian bagi negara-negara Pasifik Barat dan menjadi perhatian penting bagi AS, (4) Menyediakan persenjataan defensive untuk Taiwan, (5) Meyakinkan hak untuk melawan segala macam bentuk serangan atau koersi yang akan mengancam keamanan atau sistem ekonomi dan sosial rakyat Taiwan (Chang, 2001:66).

Menyikapi pengesahan TRA, China menyampaikan keberatannya dan mempertanyakan komitmen AS. Meski marah, namun Beijing tetap menjaga diri untuk tidak memperkeruh situasi berubah menjadi konflik terbuka (Tucker 2009, 122). Tahun 1992 masa pemerintahan George H. W. Bush, hubungan China-Amerika pernah mencapai titik yang paling buruk. AS menjual 150 buah pesawat F-16 kepada Taiwan sehingga merupakan nilai penjualan senjata ke Taiwan terbesar sepanjang sejarah.

Hal ini berarti, pemilihan kebijakan ofensif dalam upaya reunifikasi Taiwan oleh China akan memiliki dampak langsung dengan AS. Beijing telah membuktikan eratnya hubungan AS-Taiwan yang diikat oleh TRA sewaktu terjadi ketegangan di selat Taiwan, AS mengirim dua kapal induknya, USS Independence dan USS Nimitz. Hal lain yang perlu dikemukakan bahwa dalam National Defense Strategy tahun 2008, AS memberikan perhatian khusus terhadap modernisasi militer China, yang secara khusus ditujukan kepada kemungkinan konflik dengan Taiwan. Demikian halnya dalam National Security Strategy tahun 2010, AS akan terus memonitor program modernisasi militer China dan bersiap untuk memastikan bahwa kepentingan dan sekutu-sekutunya, dalam lingkup regional atau global, tidak terkena dampak negatif dari program China tersebut (Prasetya, tt: 62). Hal lain yang menjadi pertimbangan Tiongkok adalah kekuatan militer AS. Baik globalfirepower maupun Stockholm International Peace Research Institute (SIPRI) menempatkan militer AS jauh lebih unggul di atas kemampuan militer Tiongkok. Pada tahun 2002 anggaran mencapai angka US\$ 356.720 milyar, dan terus meningkat dua kali lipatnya hingga US\$ 698.281 milyar pada tahun 2010. Sedangkan anggaran belanja RRC sebesar 262 triliyun yuan pada tahun 2002, dan meningkat empat kali lipat pada tahun 2010 menjadi sebesar 808 triliyun yuan (Prasetya, tt: 58). Besaran anggaran belanja militer AS masih terlampau jauh untuk dikejar ole RRC. Besarnya belanja AS enam kali lebih banyak dari pada RRC. 


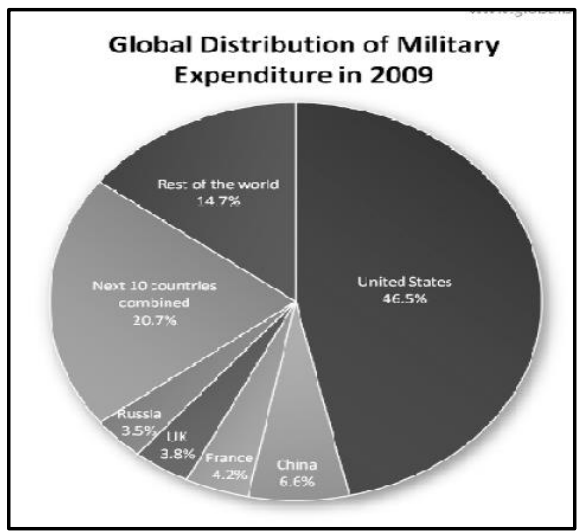

Gambar 1. Distribusi belanja militer global

(Sumber: Prasetya, tt: 58)

China memilih untuk menggunakan pilihan yang berseberangan. Beijing memilih untuk meningkatkan mutual trust di bidang politik, menyelenggarakan dialog dan konsultasi, serta mewujudkan kesepakatan pertukaran surat, transportasi dan perdagangan, sebagaimana meningkatnya hubungan ekonomi dan finansial di antara China dan Taiwan.

Begitupun juga dengan AS dengan meredahnya konflik China-Taiwan yang ditunjukan dengan intensitas kerjasama-kerjasama bilateral antara dua negara, tidak menggoyahkan AS untuk berhenti bekerjasama militer dengan Taiwan. Dimana AS tetap menjadi pemasokan senjata utama Taiwan. Sejak rezim Jimmy Carter, George Walker Bush, Barack Obama hingga memasuki rezim Donald Trump-pun Amerika Serikat masih terus konsisten menjadi provider persenjataan bagi Taiwan dan terus menunjukkan komitmennya untuk menjalin kerjasama dengan Taiwan. Hal ini terjadi bukan hanya karena AS memiliki komitmen untuk melakukan apa saja guna mengakomodir kepentingan negaranya, melainkan AS memiliki kepentingan-kepentingan lainnya yang bersifat pribadi dan ada sesuatu yang tersembunyi yang ingin dicapai AS dalam hubungan kerjama militer ini, serta menjaga kepentingan dan tujuan awal negaranya.

\section{PENUTUP}

Konflik China-Taiwan disebabkan adanya perbedaan pandangan mendasar mengenai satus Taiwan sehingga antara keduanya gagal menemukan titik temu di antara keduanya. Pemerintah Taiwan berpandangan bahwa Taiwan merupakan sebuah negara yang berdaulat dengan nama resmi Republic of China (ROC)/Taiwan. Sebaliknya, pemerintah China menegaskan bahwa eksistensi Taiwan telah berakhir sejak tahun 1949 yang selanjutnya digantikan oleh PRC. Oleh karena itu, pemerintah China menilai bahwa Taiwan tidak berhak mengklaim sebagai pemerintah yang sah di Taiwan.

Sedangkan keterlibatan Amerika Serikat dalam konflik Cina-Taiwan disebabkan kebangkitan China baik dalam bidang ekonomi dan militer telah meningkatkan ketakutan dan ancaman terutama pada sekutu-sekutu Amerika Serikat terutama Taiwan sebagai sekutu lama. Amerika Serikat memperlihatkan sikap yang ambigu terhadap keberpihakannya dengan China atau Taiwan. Sikap AS kepada China dengan menyetujui Joint Communique pada tahun 1979 sedangkan dengan Taiwan membuat kesepakatan Taiwan Relations Act (TRA). Di mata Amerika Serikat, Taiwan memiliki posisi yang strategis baik di bidang ekonomi, politik maupun militer. Bidang ekonomi, Taiwan merupakan mengimpor senjata terbesar dari AS. Sedangkan bidang politik, Taiwan menunjukan sikap pro Barat. Hal inilah yang mendorong AS menjaga kawasan Asia Pasifik termasuk Taiwan agar sekutu-sekutunya tidak jatuh ketangan komunis. Sedangkan Aspek militer, AS membangun pangkalan militernya du Taiwan untuk "memperingatkan" Cina maupun Rusia agar tidak mengganggu sekutu-sekutu AS di Asia Pasifik. 


\section{Daftar Pustaka}

American Institute in Taiwan. Taiwan Relations Act: Public Law 96-8, 96 Congress," January 1, 1979 http://www.ait.org.tw/en/about_ait/, diakses tanggal 10 Okt 2018.

BBC, China and Taiwan in First Government Talks, https://www.bbc.co.uk/news/world-asia-china26129171 diakses pada 11 Maret 2018 pukul 18.30.

Bendini, Roberto, 2016, United States-China Relations: A Complex Balance Between Cooperation and Confrontation. Directorate General for External Policies Policy Department, European Union.

Bullard, Monte R., 2004, "Strait Talk: Avoiding A Nuclear War Betwaan The U.S. and China Over Taiwan." Monterey Institute of International Studies.

Cecep Zakarias El Bilad, 2014, Sejarah dan Perkembangan Hongkong, November 19, 2008, 11:19 pm.https://zakariaselbilad.wordpress.com/2008/11/19/sejarah-dan-perkembangan-hongkong. Diakses 2 Januari 2018.

Chang, James C. P., 2001, Weatherhead Center for International Affairs Harvard University.

CNN Indonesia. Menengok hubungan Taiwan-China: Musuh Tapi Mesrah. https://www. cnnindonesia.com/internasional/20151105135044113-89679/menengok-hubungan-taiwanchina-musuh-tapi-mesra.diakses pada 7 maret 2018. Pukul 15.22.

Darini, Ririn, 2010, Garis besar Sejarah China Era Mao, Skripsi, Yogyakarta: Jurusan Pendidikan Sejarah, Universitas Negeri Yogyakarta.

Darmawan, Fajrian Eka Budi, 2015, Dampak Kerjasama Militer Amerika Serikat-Taiwan terhadap Hubungan Amerika Serikat-China, Jurnal JOM FISIP, Vol. 2, No. 2, Oktober 2015, Jurusan Hubungan Internasional - Fakultas Ilmu Sosial dan Ilmu Politik Universitas Riau.

Deng, Yong, 2008, China's Struggle for Status. New York: Cambridge University Press.

Islami, Fahmi, 2013, Kebijakan Luar Negeri Taiwan di Bawah Presiden Ma Ying-Jeou (20082012) di BidangKeamanan, Ekonomi,dan Identitas dalam Hubungan antara Sela Taiwan dan China, Skripsi, Jurusan Hubungan Internasional, Universitas Indonesia.

Kan, Shirley A., 2014, China/Taiwan: Evolution of the "One China"Policy-Key Statements from Washington,Beijing, and Taipei, Congressional Research Service, Informing the legislative debate since 1914.

Mubah, A. Safril, 2014, Kajian Historis atas Kompleksitas Isu Taiwan dalam Hubungan China dan Amerika Serikat, jurnal Global \& Strategis, Th. 8, No. 2. Juli-Desember 2014, Departemen Hubungan Internasional, Universitas Airlangga.

Prasetya, Dion Maulana, tt, Strategi Defensif China dalam Merespon Kebijakan Amerika Serikat atas Taiwan. Alumnus Jurusan Hubungan Internasional Universitas Muhammadiyah Malang (UMM).

Sari, Suwarti \& Yanyan Mochamad Yani, 2017, Revitalisasi Hubungan Amerika Serikat di Asia Pasifik, Dinamika Global, Volume 02, No.02, Desember 2017.

Soebantardjo, 1960, Sari Sejarah: Asia Australlia, jilid I, Yogyakarta.

Sukisman WD. 1987, Sejarah China Kontemporer, Jilid I dan II; Jakarta: PT Prdnya Paramita.

Tucker, Nancy Bernkopf, 2009, Strait Talk: United States-Taiwan Relations and the Crisis with China. Massachusetts: Harvard University Press. 
Ye, Lang, Zhenggang Fei, and Tianyou Wang, 2007, China: Five Thousand Years of History and Civilization, Kowloon, Hong Kong: City U of Hong Kong. 